\title{
Dust altitude and infrared optical depth from AIRS
}

\author{
C. Pierangelo, A. Chédin, S. Heilliette, N. Jacquinet-Husson, and R. Armante \\ Laboratoire de Météorologie Dynamique/Institut Pierre Simon Laplace, Ecole Polytechnique, Palaiseau, France
}

Received: 14 May 2004 - Published in Atmos. Chem. Phys. Discuss.: 21 June 2004

Revised: 31 August 2004 - Accepted: 6 September 2004 - Published: 13 September 2004

\begin{abstract}
We show that mineral dust optical depth and altitude can be retrieved from the Aqua - Advanced Infrared Radiation Sounder (AIRS) measurements. Sensitivity studies performed with a high spectral resolution radiative transfer code show that dust effect on brightness temperatures may reach about 10 Kelvins for some channels. Using a LookUp-Table approach, we retrieve not only the $10 \mu \mathrm{m}$ optical depth but also the altitude of Saharan dust layer, above the Atlantic Ocean, from April to September 2003. A key point of our method is its ability to retrieve dust altitude from satellite observations. The time and space distribution of the optical depth is in good agreement with the Moderate resolution Imaging Spectroradiometer (MODIS) products. Comparing MODIS and AIRS aerosol optical depths, we find that the ratio between infrared and visible optical depths decreases during transport from 0.35 to 0.22 , revealing a loss in coarse particles caused by gravitational settling. The evolution of dust altitude from spring to summer is in agreement with current knowledge on transport seasonality.
\end{abstract}

\section{Introduction}

The last report of the Intergovernmental Panel on Climate Change (IPCC, 2001) emphasized the very poor level of understanding of aerosol radiative forcing. Amongst other aerosol species, mineral dust is a major contributor to total aerosol loading and has been the subject of an increasing number of studies. However, most remote sensing studies focus on the solar spectrum, whereas the closure of the terrestrial radiative balance also needs knowledge of the dust effect on terrestrial and atmospheric infrared radiation (Vogelmann et al., 2003). Yet, the dust radiative forcing in the thermal infrared cannot be well quantified from data measured in the visible spectrum, because refractive index spectra, highly variable, are not reliable enough both in the infrared and in the visible, and because the infrared and visi-

Correspondence to: C. Pierangelo

(clemence.pierangelo@1md.polytechnique.fr) ble spectra are not sensitive to the same ranges of particles sizes. The infrared radiation is above all sensitive to particles in the size range from about half a micrometer to about ten micrometers, depending on the wavelength and on the refractive index of the aerosol. Here, "thermal infrared", "terrestrial and atmospheric infrared", or more simply "infrared" refers to the radiation emitted by the Earth surface and the atmosphere in the wavelength range 3 to $15 \mu \mathrm{m}$, as opposed to the near-infrared radiation mostly emitted by the sun.

In addition to measuring aerosol radiative forcing on terrestrial and atmospheric radiation, remote sensing in the thermal infrared has several advantages: observations are available both for daytime and nighttime, vertical sounders give the possibility to retrieve dust layer altitude, and dust detection is possible over desert, thus providing a way to monitor dust sources (Chomette et al., 1999). The ability to retrieve dust altitude may be of great interest for the study of dust deposit on the ocean and its fertilization by iron. Also, through the spectral variations of dust optical properties, information on its mineralogical composition may be retrieved (Sokolik, 2002). Besides, if not accounted for, the presence of an aerosol layer can contaminate atmospheric variables retrieved from vertical sounder observations, as temperature or water vapor profiles (e.g. Weaver et al., 2003; Highwood et al., 2003)

The new generation of high spectral resolution infrared sounders (like AIRS launched in May 2002 onboard Aqua) shows promising capabilities to retrieve aerosol properties from space, compared to wide-band radiometers like MODIS (Sokolik, 2002). Recent studies also proved the ability of AIRS observations in monitoring clouds and volcanic aerosol (Ackerman et al., 2004).

A subset of 324 channels that cover the thermal infrared spectrum, from 3.7 to $15.4 \mu \mathrm{m}$, is currently distributed by the NOAA/NESDIS (Goldberg et al., 2003) and archived at Laboratoire de Météorologie Dynamique since 1 April 2003. In the following, channels will be identified by their number in the range $1-324$. 
In this paper, we retrieve the infrared optical depth and altitude of mineral dust aerosol layer over ocean from AIRS radiances. This is achieved using simulations from a high spectral resolution radiative transfer code showing that the longwave channels $(8-12 \mu \mathrm{m})$ are mostly sensitive to the altitude of the dust whereas the shortwave channels $(4 \mu \mathrm{m})$ are mostly sensitive to the dust optical depth. This behavior allows both properties to be retrieved simultaneously. The method developed in this paper for the processing of AIRS observations consists in comparing the radiances observed from 8 carefully selected channels to pre-computed simulated radiances. Results for the northern tropical Atlantic ocean for a 6 month period (April to September 2003) are presented. Retrieved dust optical depths are compared with MODIS aerosol optical depths. The time and space patterns of the retrieved altitude are then discussed.

\section{Sensitivity of infrared radiances to dust aerosol}

Because dust single scattering albedo in the infrared is not negligible (Dufresne et al., 2002), modeling AIRS infrared radiances in presence of dust requires a radiative transfer model including scattering and adapted to the high spectral resolution of AIRS.

However, most line-by-line radiative transfer (RT) codes do not account for scattering, whereas RT codes including scattering are low spectral resolution band models. We solved this problem by coupling the fast line-by-line Automatized Atmospheric Absorption Atlas " $4 \mathrm{~A}$ " model (Scott and Chédin, 1981) and the discrete ordinate algorithm (DISORT) (Stamnes et al., 1988) adapted to the "4A" vertical layering (40 pressure levels from 1013 to $0.05 \mathrm{hPa}$, see http://ara.lmd.polytechnique.fr/ for more information). However, such a code, being monochromatic, and consequently very accurate, is too much time-consuming for remote sensing applications. The correlated k-distribution method (e.g. Lacis and Oinas, 1991) cannot be easily implemented, because of different gas lines overlap. Solutions to this problem are discussed in Yang et al. (2000) but they increase the computation time. The approach used here simply consists in decreasing the spectral resolution of " $4 \mathrm{~A}$ ": for each level, the molecular transmittance is "contracted" (i.e. carefully averaged over small spectral intervals). The comparison between the "contracted" code and the reference code provides a way to choose the "best" contraction, i.e. the poorer resolution that keeps the error below an acceptable level $(0.05 \mathrm{~K}$ in this study).

The effect of mineral dust on AIRS brightness temperatures (BT) was then simulated for different visible aerosol optical depths (AOD), layer altitudes, surface emissivities, and size distributions. The assumed vertical distribution of the dust is very simple: for each simulation, only one "4A" layer contains the whole dust load, homogeneously distributed. The thickness of a " $4 \mathrm{~A}$ " layer in the tropo- sphere extends from $500 \mathrm{~m}$ (near the surface) to $800 \mathrm{~m}$ (near the tropopause). So, by altitude, we mean the middle of the " $4 \mathrm{~A}$ " layer loaded with dust; changing the altitude is changing the " $4 \mathrm{~A}$ " layer containing the aerosol. The results of simulations are shown in (Figs. 1a-d), together with the range of variation of each variable. For each figure, only one variable is changed, the other keeping their "reference" value: $\mathrm{AOD}=1.5$, altitude $=2400 \mathrm{~m}$, surface emissivity $=0.98$, dust model=MITR (mineral transported model from the Optical Properties of Aerosols and Clouds (OPAC) data base (Hess et al., 1998), archived in the Geisa spectroscopic catalog (Jacquinet-Husson et al., 1999)). For Fig. 1a-d simulations and for the whole study, only night-time situations are considered, to prevent solar contamination of the shortwave infrared channels. The dust signature may reach $10 \mathrm{~K}$ and increases with AOD and altitude. The dust altitude is a crucial point: the dust signature increases by a factor of 3 to 4 when the altitude increases from $800 \mathrm{~m}$ to $4000 \mathrm{~m}$. Figs. 1a$\mathrm{b}$ show that shortwave channels $(3-5 \mu \mathrm{m})$ are mostly sensitive to the AOD, whereas longwave channels $(8-12 \mu \mathrm{m})$ are mostly sensitive to the altitude, explaining why it is possible to retrieve both the AOD and altitude of a dust layer using AIRS measurements. The impact of the size distribution is not as strong as that of the AOD or altitude. This agrees with Sokolik et al. (1998) simulations showing that, for many dust samples, the shape of extinction coefficient at infrared wavelengths remains almost unchanged when the mean dust radius increases. This relative insensitivity to size distribution justifies to a good approximation the fact that only one model of mineral dust (MITR), valid far from the sources, is considered. For this reason and because the aerosol signature depends on surface emissivity, our approach is presently limited to the ocean.

\section{Method}

\subsection{Channel selection}

Channels the most appropriate to the retrieval of the two variables of interest, dust altitude and AOD, are first selected. Selection criteria are: (i) sensitivity to dust (ii) no sensitivity to ozone (iii) reduced sensitivity to water vapor. Regarding the sensitivity to dust, a channel is selected either because its sensitivity is high, or because it is well correlated with a far more sensitive channel over a wide range of clear-sky atmospheric situations. This last type of selected channels provide information on other atmospheric variables, as the temperature profile, thus constraining the retrieval.

Redundant channels (i.e. with close transmittance profiles) are removed. This way, 8 channels were selected, both in the $8-12 \mu \mathrm{m}$ window and near $4 \mu \mathrm{m}$ (Table 1). A proper coverage of the lower tropospheric column is ensured by selecting channels with surface transmittance varying in the range $0.25-0.9$, because the lower the surface transmittance, the 

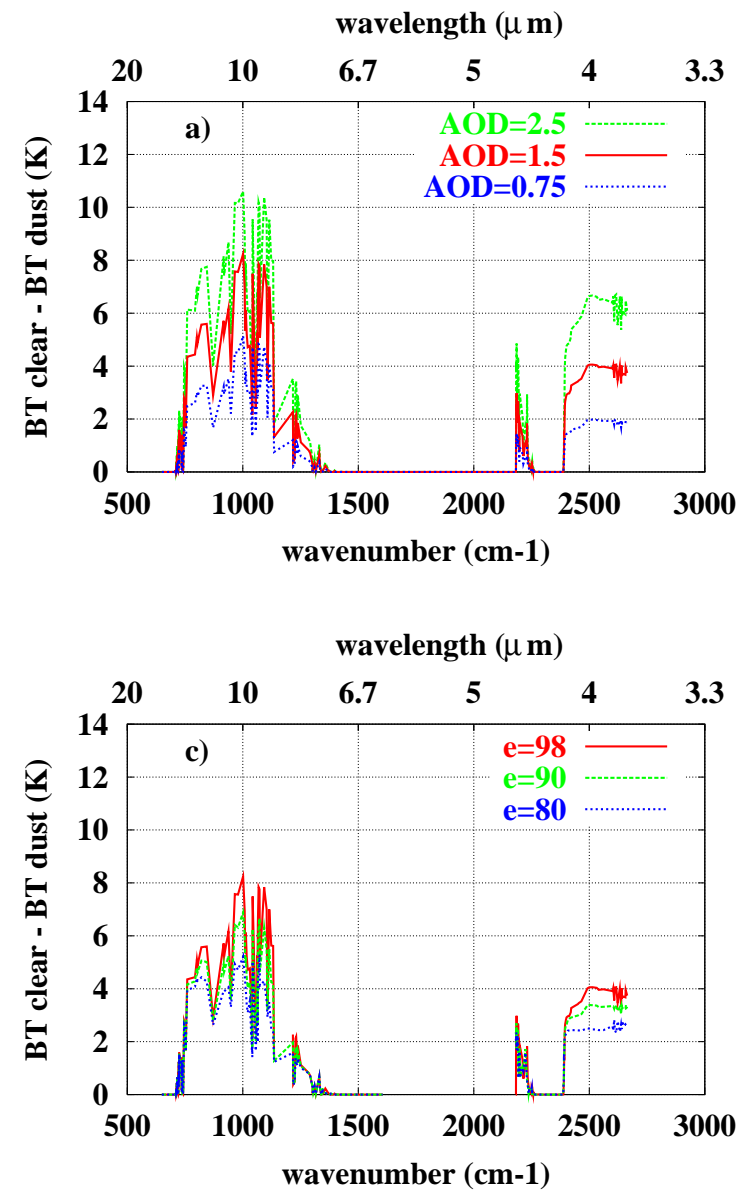
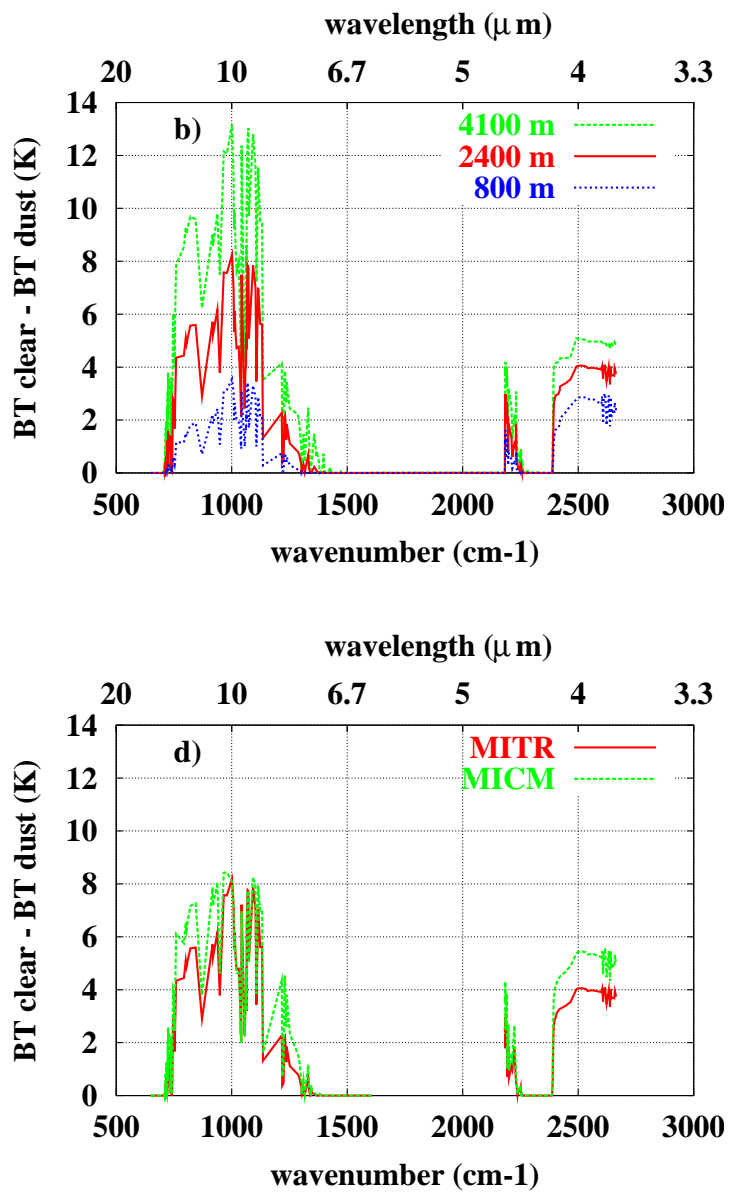

Fig. 1. Effect of mineral dust on AIRS brightness temperatures for 324 channels, as a function of aerosol optical depth (a), aerosol layer altitude (b), surface emissivity (c), and aerosol model (d) (MITR=mineral transported, MICM=mineral coarse mode). "Reference" values: $\mathrm{AOD}=1.5$, altitude $=2400 \mathrm{~m}$, surface emissivity $=0.98$, dust model=MITR (red line).

higher the altitude of the channel weighting function peak. Note that channel 313 and channel 315 , even very close (3.83 and $3.82 \mu \mathrm{m}$ ), have a different surface transmittance. This means that they are not sensitive to the same altitude levels and illustrates the potential of high spectral resolution observations for vertical sounding.

\subsection{A look-up-table approach}

For each selected channel, look-up-tables (LUT) were precomputed, a usual approach for aerosol remote sensing (Tanré et al., 1997). Contrary to the visible, infrared satellite radiances are above all sensitive to the thermodynamic state of the atmosphere (water vapor and temperature profiles, in particular). As a consequence, the LUT must be computed for a large selection of atmospheric situations (here, about two third of the 872 tropical situations from the climatological data base TIGR (Thermodynamic Initial Guess retrieval) (Chédin et al., 1985; Chevallier et al., 1998)). For each atmospheric situation, and each of the 8 selected channels, the LUT contain BT computed for 5 dust loading (corresponding to visible AOD 0.0, 0.4, 0.8, 1.5, 2.5) and 4 altitudes of the layer (from 500-1000 m to 5300-6000 m). Finally, brightness temperatures are linearly interpolated for other AOD and altitudes.

Usually, what is intended by AOD is the $0.55 \mu \mathrm{m}$ AOD. However, such a choice is not adapted to remote sensing in the infrared from AIRS measurements in the $4-12 \mu \mathrm{m}$ domain. So, we have chosen to retrieve the optical depth at $10 \mu \mathrm{m}$. Thus, the aerosol spectroscopic model used in building the LUT is required to be valid only over the $4-12 \mu \mathrm{m}$ band and not up to visible wavelengths.

The retrieval from a measured set of brightness temperatures is based on the search for the closest set in the LUT, according to the normalized distance $D$ :

$$
\begin{aligned}
D= & \sum_{i=1,8} \frac{\left(B T_{\mathrm{calc}}^{i}-B T_{\mathrm{obs}}^{i}\right)^{2}}{\sigma_{i}^{2}}+ \\
& \sum_{j=1,5} \frac{\left(\Delta B T_{\mathrm{calc}}^{j}-\Delta B T_{\mathrm{obs}}^{j}\right)^{2}}{\sigma_{j}^{2}}
\end{aligned}
$$


Table 1. AIRS selected channel number, wavenumber, wavelength and mean surface transmittance over the tropical situations of the climatological database "Thermodynamic Initial Guess Retrieval" (TIGR). 2 of the 8 channels selected for the retrieval of aerosol properties belong to the shortwave infrared (near $4 \mu \mathrm{m}$ ), 6 belong to the 8 to $12 \mu \mathrm{m}$ band.

\begin{tabular}{cccc}
\hline AIRS channel & $\begin{array}{c}\text { wavenumber } \\
\left(\mathrm{cm}^{-1}\right)\end{array}$ & $\begin{array}{c}\text { wavelength } \\
(\mu \mathrm{m})\end{array}$ & $\begin{array}{c}\text { surface } \\
\text { transmittance }\end{array}$ \\
\hline 134 & 844 & 11.85 & 0.55 \\
135 & 871 & 11.48 & 0.25 \\
140 & 965 & 10.36 & 0.68 \\
166 & 1074 & 9.31 & 0.35 \\
177 & 1228 & 8.14 & 0.55 \\
179 & 1237 & 8.08 & 0.25 \\
313 & 2608 & 3.83 & 0.6 \\
315 & 2616 & 3.82 & $>0.9$ \\
\hline
\end{tabular}

where $B T_{\text {calc }}^{i}$ and $B T_{\text {obs }}^{i}$ are, respectively, the calculated and observed brightness temperatures of channel $\mathrm{i}$, and $\Delta B T^{j}$ stands for a difference between two channels. To be selected as the closest to the observations, a set of brightness temperatures within the LUT must have values similar to the observations for each channel (first term in Eq. 1), but also differences between BT close enough to differences between observed BT (second term in Eq. 1). The differential aspect of this second term adds an important constrain to the proximity recognition. After several trials, best results were obtained for the 5 following couples of channels $(j=1,5)$ : $140-134$, 166-135, 177-134, 313-177, 315-177.

This algorithm was tested with independent synthetic sets of brightness temperatures, and the percentage of good retrieval of AOD and altitude increased from $60 \%$ to $90 \%$ when the constrain on differences was introduced (second term in Eq. 1). This good score demonstrates the quality of the method and proves that the set of atmospheric situations considered here is sufficient to reproduce the atmospheric natural variability in terms of temperature and water vapor profiles. Also, if the distance $D$ (see Eq. 1) is too large, the corresponding retrieval is rejected, which prevents a situation too far from the LUT (or contaminated by remaining clouds see Sect. 4.2) to be considered.

The algorithm has to account for the noise inherent in real observation data. To do so, the error caused by the noise in brightness temperatures on the distance $D$ between the observations and the closest situation in the LUT is first calculated. Then, a circle centered on the observed set of brightness temperature, with radius the minimum distance plus its error, is drawn. The retrieved AOD and altitude are the average of the AOD and altitude of all the situations in the LUT falling into this circle. Their standard deviation provides an estimate of the dispersion of the retrieval.
3.3 Robustness of the retrieval algorithm to aerosol model

We first checked the robustness of the retrieval to a potential error on the aerosol model, i.e. on its size distribution, shape, and refractive indices. Considering a lognormal size distribution and sampling its effective radius in the range 0.5 to $3 \mu \mathrm{m}$, simulations for almost 300 atmospheres, $3 \mathrm{AOD}$ and 2 different altitudes show that the effect of a change in the size distribution on the retrieved AOD and altitude is $10 \%$ at the maximum. The effect of shape has been studied with the TMatrix code written by Mishchenko et al. (2002), assuming prolate spheroids with aspect ratio of 2. Although this is not a realistic representation of dust (it would be more accurate to use an aspect ratio distribution) it gives an upper value for the asphericity impact, since averaging the optical properties over several aspect ratio tends to decrease the asphericity effect. The impact on the retrieval is still smaller than the size impact, below $10 \%$.

Although the size and shape effect can be examined quite easily, by continuously changing the effective radius or aspect ratio of dust, the impact of refractive index is trickier since it depends on both the imaginary and real part of the refractive index at the central wavelengths of the 8 channels. Besides, the only measurements of saharan dust refractive indices in the infrared far from the sources are those made by Volz (2003) for Saharan dust collected at Barbados. Fouquart et al. (1987) reported measurements of Saharan dust in Niger. The OPAC data set is a revised version of the data published in the book from d'Almeida et al. (1991), and the OPACmineral transported (MITR) aerosol refractive index mostly comes from the measurements from Volz (2003).

A sensitivity study using the OPAC-MITR data set, the "Sahara dust-Barbados" data set (Volz, 2003), the "mineral" and "dust-like" data set (d'Almeida et al., 1991) (aiming at describing soil dust rather than desert dust), and the refractive indices reported in Fouquart et al. (1987) has been conducted. We found that if the real aerosol is described by the original Volz data set, instead of the MITR model, then the optical depth might be slightly underestimated by about $10 \%$, and the altitude slightly overestimated by $10 \%$, in agreement with the fact that both data sets are very close. However, if the real aerosol is described by one of the three other data sets, the optical depth retrieved by the algorithm, even for an input $10 \mu \mathrm{m} \mathrm{AOD}$ of the order of 0.9 , is always below 0.5 . As the retrieval applied to real observation data leads to values as high as 1 or more, we can deduce that the "mineral", "dust", and "Fouquart" data sets do not represent the observed aerosol. This is consistent to conclusions of Sokolik et al. (1998) that the "Sahara dust-Barbados" refractive indices should be used to model optical properties of longliving airborne dust originating from the Sahara over the Atlantic Ocean. 
3.4 Robustness of the retrieval algorithm to the dust vertical distribution

The vertical distribution of dust may be more complicated than a single homogeneous layer, as observations show that transport sometimes occurs in two or three distinct layers. Thus, the (unknown) physical thickness of the layer and the number of dust layers are two potential sources of error that have been investigated. As explained in Sect. 2, the altitude retrieved is the average altitude of the dust, i.e. the altitude at which half of the dust optical depth is below and half of the optical depth is above. If the layer is homogeneous, it is the middle of this layer. For example, a layer located between 1500 and $2000 \mathrm{~m}$ has a mean altitude of $1750 \mathrm{~m}$. A sensitivity study has been conducted for a very thick layer case (more than $3 \mathrm{~km}$ ) and for a 2-layer case (one layer between 2000 and $2800 \mathrm{~m}$, and a second layer between 3700 and $4600 \mathrm{~m}$ ), for about 300 atmospheric situations: in both cases the mean retrieved altitude over the atmospheric dataset agrees by $200 \mathrm{~m}$ to this definition of the altitude. Furthermore, even if the vertical distribution of the dust cannot be retrieved, a homogeneous layer located at the retrieved altitude is an infrared optical equivalent to the real vertical profile. Therefore, it is appropriate for computing dust infrared forcing.

\subsection{Contamination by other aerosol species}

Possible contamination by other aerosol species has also been considered. Biomass burning or anthropogenic aerosol, like sulfates or soot, does not contain as many coarse particles as dust. As a consequence, their infrared to visible extinction ratio is very low (of the order of $1 / 20$ ) and so their infrared optical depth is negligible compared with the dust optical depth. Except dust, sea-salt is the only aerosol with a predominant coarse mode. However, because its optical depth is quite low (of the order of 0.1) and because sea-salt aerosol is located in the marine boundary layer, its effect on the retrieval is negligible: simulations have shown that an amount of sea-salt with $\mathrm{AOD}=0.2$ increases the retrieved dust AOD by only 0.03 .

\section{Application to AIRS observations}

\subsection{Radiative transfer model bias removal}

Because the LUT are built with simulated data, their application to real data implies that eventual brightness temperature systematic biases between simulations and observations have been eliminated. This may be done by comparing simulations and observations for a set of collocated satellite observations and analyses from the European Centre for MediumRange Weather Forecasts, for clear sky situations. These comparisons were done for 15 days chosen at random in the period February to September 2003, on the whole tropical
Table 2. Cloud tests for the retrieval of dust properties. All these tests are threshold tests. Tests 1 and 2 are based on differences between two AIRS channels. Note that the effect of dust on the difference is opposite to the effect of clouds. Test 3 consists in the prediction of AIRS channel 286 brightness temperature with a linear regression of 3 AMSU channels.

\begin{tabular}{ccccc}
\hline Test number & AIRS channel & clear sky & cloud & dust \\
\hline 1 & BT 315-BT 140 & $>0.5 \mathrm{~K}$ & $<0.5 \mathrm{~K}$ & $>1 \mathrm{~K}$ \\
2 & BT 313-BT 177 & $<1.5 \mathrm{~K}$ & $>1.5 \mathrm{~K}$ & $<0 \mathrm{~K}$ \\
3 & BT 286-reg(AMSU 5,6,8) & $>0 \mathrm{~K}$ & $<0 \mathrm{~K}$ & $>0 \mathrm{~K}$ \\
\hline
\end{tabular}

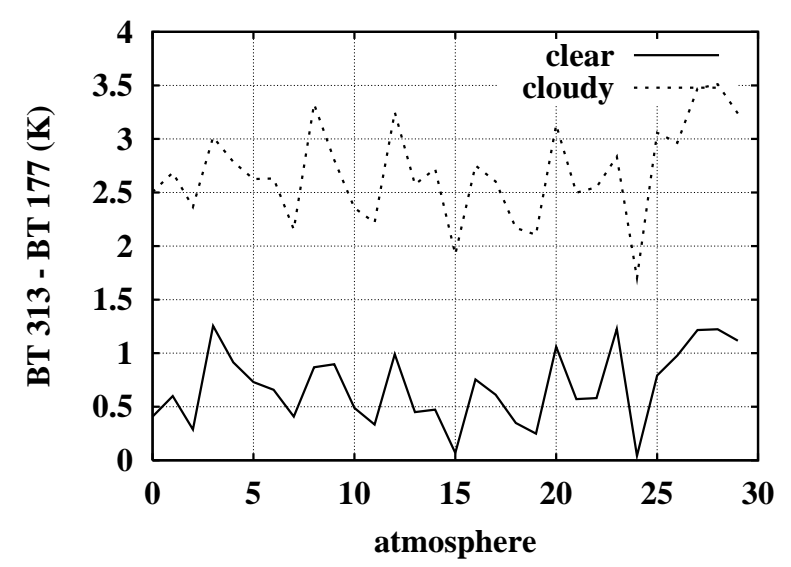

Fig. 2. Principle of cloud test: difference between channel $313(3.83 \mu \mathrm{m})$ brightness temperature and channel $177(8.14 \mu \mathrm{m})$ brightness temperature from radiative transfer simulations for 30 atmospheric tropical situations, for both clear and cloudy conditions. The threshold for this test is $1.5 \mathrm{~K}$. The impact of dust on this difference is the opposite of the impact of clouds: it decreases BT 313-BT 177.

zone, and for each channel. By adding the average bias (calculated - observed), the observed BT are scaled to the LUT BT reference frame. This procedure also prevents the background aerosol, whose loading shows a weak temporal variability, to contaminate the retrieval.

\subsection{Cloud mask}

Separating the signature of the aerosol from that of the clouds is a tricky problem for aerosol remote sensing (King et al., 1998). Cloud masks usually aim at providing highconfidence clear-sky pixels, and may consequently consider aerosol-loaded situations as cloudy. Therefore, a special cloud mask has been developed. Radiative transfer simulations help us to find couples of channels which are well correlated over a wide range of atmospheric situations except cloudy ones. If the difference between these channel BT reaches a certain threshold, the pixel is flagged as cloudy 
Table 3. Comparison between AIRS aerosol-dedicated cloud mask and MODIS cloud mask, for 27 April 2003, over the Atlantic Ocean $\left(30^{\circ} \mathrm{S}-30^{\circ} \mathrm{N}, 0^{\circ}-60^{\circ} \mathrm{W}\right)$, for $0.25^{\circ}$ grid boxes. A box is flagged cloudy for MODIS if the average cloud confidence level is above $90 \%$, clear if it is below $10 \%$ and partially cloudy for other situations. A box is flagged cloudy for AIRS if more than $90 \%$ of the pixels inside it are flagged cloudy, clear if less than $10 \%$ of the pixels are flagged cloudy, and partially cloudy for other situations. Results are given in $\%$.

\begin{tabular}{c|ccc|c}
\hline & $\begin{array}{c}\text { MODIS } \\
\text { cloudy }\end{array}$ & $\begin{array}{c}\text { MODIS } \\
\text { partially } \\
\text { cloudy }\end{array}$ & $\begin{array}{c}\text { MODIS } \\
\text { clear }\end{array}$ & total \\
\hline $\begin{array}{c}\text { AIRS cloudy } \\
\text { AIRS partially cloudy }\end{array}$ & 51.8 & 4.7 & 0.2 & 55.7 \\
AIRS clear & 11.7 & 16.1 & 9.0 & 36.8 \\
\hline total & 67.4 & 23.3 & 9.3 & 100 \\
\hline
\end{tabular}

(see Fig. 2). In order to prevent a pixel to be flagged as cloudy when dusty, the effect of dust must be different to the effect of clouds. For instance, if the presence of clouds decreases the difference between two channels, the presence of dust should increase this difference or keep it constant. Following this technique, two tests have been settled, using channels within the 8 selected channels (see Table 2). A third test uses 3 channels of the Advanced Microwave Sounding Unit (AMSU 5, 6 and 8) to predict an AIRS channel BT (channel 286 at $2393.1 \mathrm{~cm}^{-1}$ ). As most clouds and aerosols have negligible impact on AMSU BT, when the predicted AIRS BT is too far from its measured value, the pixel is considered as cloudy.

A comparison with the MODIS/Aqua cloud mask (product MYD06_L2) for simultaneous and co-located scenes has been done for one day (27 April 2003), at a regional scale, over the Atlantic Ocean $\left(30^{\circ} \mathrm{S}-30^{\circ} \mathrm{N}, 0^{\circ}-60^{\circ} \mathrm{W}\right.$ ) (see Table 3). Because of the different spatial resolution of the two instruments, comparison is made over 0.25 degree grid boxes. $90.7 \%$ of these boxes are flagged cloudy or partially cloudy by MODIS, versus $63.2 \%$ for AIRS. More than $85 \%$ of the discrepancies are caused by pixels considered cloudy by MODIS and not cloudy (clear or potentially dusty) by AIRS, and not the opposite. There are two main causes to this important difference. First, MODIS cloud fractions for night-time data are too high over the oceans, (artifact of the cloud mask, see Mahesh et al., 2004), and second, there was a strong dust event over this area that night (see MODIS imagery: http://modis-atmos.gsfc.nasa. gov/MYD08_D3/browse.html), and aerosol loaded pixels are prevented to be flagged cloudy by AIRS but not by MODIS. For the whole tropical zone, and for one week in April, AIRS cloud coverage is $68 \%$. This is of the same order as the
TIROS Operational Vertical Sounder (TOVS) cloud coverage over sea in the tropics in April, 65\% (climatological data from Scott et al., 1999).

\subsection{Results and validation}

The retrieval algorithm has been applied to 6 months of observations (April to September 2003) for the north tropical Atlantic ocean $\left(0-45^{\circ} \mathrm{N}, 70-10^{\circ} \mathrm{W}\right)$, downwind of the Sahara.

The optimal way to validate the retrieved AOD would be to compare it with direct measurements, like the aerosol optical depths routinely measured by the ground-based AErosol RObotic NETwork sun-photometers (AERONET), but this raises several difficulties because: (i) routinely measured dust AOD is the visible or near-infrared AOD, not the $10 \mu \mathrm{m}$ AOD, (ii) our retrieval algorithm works with night-time data whereas all other dust AOD measurements are made during day-time and the dust optical depth above a given location (i.e. an AERONET sun-photometer) may change quite rapidly, (iii) the retrieval above a given point is possible only one day on 3 or 4 (because of Aqua/AIRS field of view and cloudy situations).

Comparing the AIRS retrievals with another satellite product is also a satisfactory approach since it has the advantage of the global scale. For satellite retrieval of aerosol properties, MODIS, onboard Terra since December 1999, is a key sensor (Tanré et al., 1997). MODIS AOD retrievals have been widely validated with AERONET (Remer et al., 2002) and compared with other satellite retrievals, model simulations and sun-photometers measurements (Kinne et al., 2003).

On Figs. 3a-b, we present the results of the comparison of AIRS retrievals with MODIS monthly visible AOD at $0.55 \mu \mathrm{m}$, on $1^{\circ} \times 1^{\circ}$ grid boxes for April to September 2003 . Visually, there is a satisfactory agreement: both aerosol loadings have the same space and time distribution. For instance, the dust loading reaches higher values in June and July. Note that, because of the bias removal procedure, AIRS product is the dust AOD whereas MODIS product is the total aerosol AOD, thus including dust but also sulfate aerosol, carbonaceous aerosol, and sea-salt. MODIS aerosol retrievals north of $30^{\circ} \mathrm{N}$ are mostly anthropogenic aerosols from North America, and consequently, further comparisons between MODIS and AIRS AOD focus on the $0^{\circ}-30^{\circ} \mathrm{N}$ latitude band.

For a single AIRS observation, a mean of about 40 situations are found in the "distance circle" associated with each retrieval (see Sect. 3.2). An estimate of the dispersion of the retrievals can be obtained from the standard deviation of theses about 40 LUT situations averaged in the retrieval algorithm. The standard deviation of the AOD and the altitude are respectively about 0.11 and $1150 \mathrm{~m}$. These values are for one single daily retrieval. One monthly $1^{\circ} \times 1^{\circ}$ box contains about 100 retrievals which increases the accuracy of the 



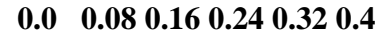

$\begin{array}{llllllllll}0.0 & 0.2 & 0.4 & 0.6 & 0.8 & 1.0\end{array}$

100014501900235028003250

(a)

(b)

(c)

Fig. 3. From left to right: monthly mean of (a) AIRS retrieved $10 \mu \mathrm{m}$ dust AOD, (b) MODIS retrieved $0.55 \mu \mathrm{m}$ aerosol AOD, and (c) AIRS retrieved altitude $(\mathrm{m})$ for the dust layer, over the northern tropical Atlantic ocean $\left(10^{\circ}-70^{\circ} \mathrm{W}, 0^{\circ}-45^{\circ} \mathrm{N}\right)$. From top to bottom: April to September 2003. Missing data for the altitude correspond to boxes where the AOD is below 0.08 . 


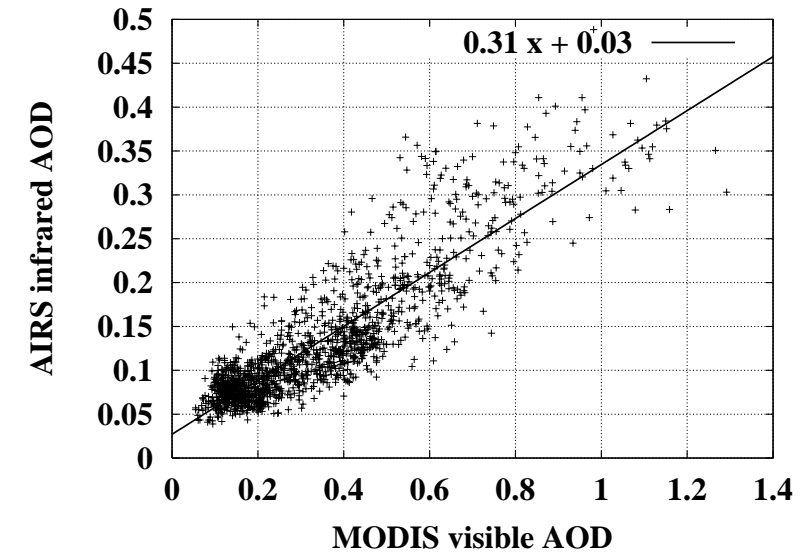

Fig. 4. AIRS retrieved $10 \mu \mathrm{m}$ AOD as a function of MODIS retrieved $0.55 \mu \mathrm{m}$ AOD, for July 2003 , for $0-30^{\circ} \mathrm{N}, 10-60^{\circ} \mathrm{W}$. Each point is the monthly mean over a $1^{\circ} \times 1^{\circ}$ box. The correlation coefficient is 0.88 and the slope of the regression line is 0.31 .

results; however the monthly standard deviation cannot be used as an estimate of the uncertainty because of the natural temporal variability of the signal.

On Fig. 4 are plotted AIRS monthly infrared AOD versus MODIS monthly visible AOD for July 2003. There is a satisfactory linear relationship between the two products, with a high correlation of 0.88 . The slope of the linear regression, i.e. the average ratio between visible and infrared AOD, is 0.31 . This is also the ratio between visible and infrared extinction coefficient, since the AOD is the product of the extinction coefficient times the total number of particles. This value compares well with ratios reported by Highwood et al. (2003) for 3 dust models: 0.34, 0.37, and 0.59. Our value, slightly smaller, is an average of the Infrared to Visible optical depth over all the Atlantic 0-30 degree band, for one month (July 2003), whereas the values given in Highwood et al. (2003) are obtained with a size distribution observed during one flight, on 25 September, 2000, from Dakar to Capo Verde Islands. Using the AERONET retrievals over Capo Verde (effective radius and width of coarse and accumulation mode, Dubovik and King, 2000), the refractive indices at $0.55 \mu \mathrm{m}$ used by MODIS retrieval, and the refractive indices at $10 \mu \mathrm{m}$ from the MITR model, we computed with a Mie radiative transfer code the infrared to visible extinction ratio. The calculated ratio varies from 0.4 to 0.55 depending on the month considered, and the AIRS to MODIS AOD ratio is of the same order of magnitude, from 0.3 to 0.5 for a small area over Capo-Verde. However, we must underline that AERONET size distribution retrievals are available only 2 to 5 days each month, whereas the AIRS to MODIS ratio is a monthly average. For the 5 other months, the AIRS to MODIS AOD ratio over the Atlantic 0-30 degree band is of the same order ( 0.22 to 0.32$)$ as in July. We also find that it steadily decreases from 0.35 to 0.22 when the distance to the sources increases (Fig. 5), which may reveal loss in coarse size particles due to gravitational settling. This is in agree-

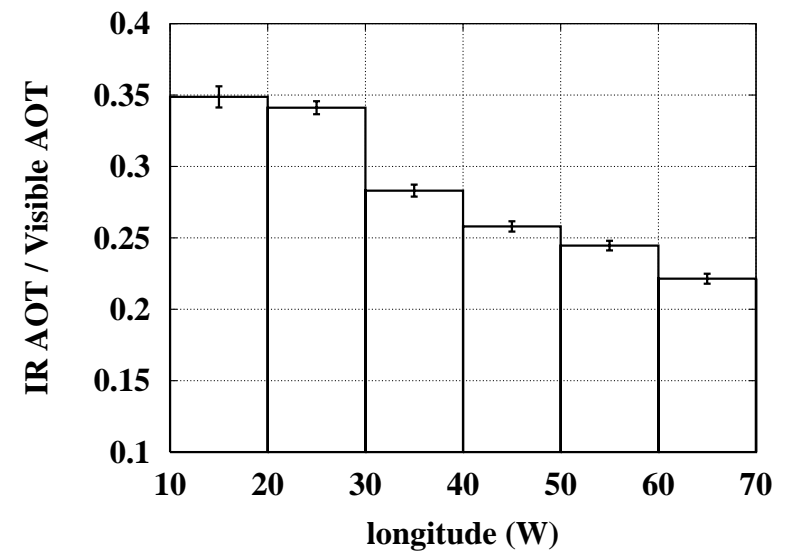

Fig. 5. Ratio of AIRS retrieved $10 \mu \mathrm{m}$ AOD on MODIS retrieved $0.55 \mu \mathrm{m}$ AOD, for July 2003 , for $0-30^{\circ} \mathrm{N}$, as a function of longitude (from the African coast to the Caribbean sea). For each longitude band, the error bar is the error on the linear regression slope.

ment with conclusions of Maring et al. (2003b) that larger mineral dust particles are preferentially removed during atmospheric transport.

Figure $3 \mathrm{c}$ shows the retrieved mean altitude of the dust layer, for the same months of April to September 2003. Validation of the retrieved altitude is not straightforward, because dust aerosol altitude observations are quite scarce and local (e.g. Immler and Schrems, 2003; Maring et al., 2003b). However, the dust layer altitude retrieved from AIRS is in agreement with in-situ observations (e.g. Prospero and Carlson, 1972; Reid et al., 2002), even if the altitude is in general somewhat lower as being a monthly mean compared to daily altitudes sometimes reaching locally higher values. Two more explanations may also be considered. First, the infrared AOD is above all sensitive to the coarse mode particles, which could stay lower than fine particles (Immler and Schrems, 2003). Second, in summer, some authors consider that dust transport occurs only in the Saharan Air Layer (SAL) (e.g. Chiapello et al., 1995), whereas other authors report observations of dust sometimes in the SAL only, and sometimes in both the SAL and the marine boundary layer (MBL) (Reid et al., 2002; Maring et al., 2003a). This second transport pattern would lead to a lower monthly mean altitude.

Also, Fig. 3c shows that the layer altitude in July decreases with latitude, from $10^{\circ} \mathrm{N}$ to $30^{\circ} \mathrm{N}$. To our knowledge, this has never been reported, but it could be explained by uplifting at the Intertropical Convergence Zone, located near $10^{\circ} \mathrm{N}$ in July. This hypothesis is in agreement with Colarco et al. (2003), whose model simulations show a positive vertical mass flux around the ITCZ. When meeting the monsoon air, air masses from north of the ITCZ, in the southwestward trade winds, are uplifted over the monsoon air (see Fig. 1 of Jonquieres et al., 1998). This mechanism could explain the south-north gradient of the dust altitude retrieved. 
Besides, we verified on Fig. 6 that summer transport occurs at higher altitudes than the "winter" transport (April and May), in agreement with Chiapello et al. (1995). The daily values reported in this figure would support the idea that, in summer, dust transport occurs sometimes in the SAL only, sometimes in both the SAL and the MBL.

\section{Conclusions}

Both the AOD and altitude of Saharan dust layers, from April to September 2003, have been retrieved, using AIRS high spectral resolution observations and pre-computed Look-upTables.

The comparison between AIRS and MODIS AOD provides a measure of the $10 \mu \mathrm{m}$ to $0.55 \mu \mathrm{m}$ extinction coefficient ratio. This ratio decreases from 0.35 to 0.22 when the distance to Sahara increases, revealing the decrease in particles size. It also shows that new products, for example the coarse mode to accumulation mode ratio, could be retrieved by AIRS and MODIS synergy. Such a product is not yet available but will be developed soon.

The retrieved dust layer altitude shows seasonal variations, with summer transport occurring at higher altitudes than spring transport. We also found a potential impact of the ITCZ on dust altitude in July. Altitude is an essential variable for the validation of dust transport models and our retrieval can bring a valuable constrain for assimilation of aerosols with 4D-Var methods. Besides, planned satellite missions with active lidars will provide vertical profiles of aerosols and clouds below the satellite track. In particular, the Calipso lidar will follow AIRS in the Aqua Train. This opens the way to promising studies combining dust vertical profile from lidar and AIRS retrieved altitude.

Also, a study could be conducted using our data set to quantify the effect of dust on AIRS retrieved temperature and water vapor profiles and their impact on meteorological forecast.

The lack of refractive index observations for saharan dust in the infrared must be underlined once again. We hope that additional measurements are to be conducted, allowing deeper study of the impact of dust composition and opening the way to promising dust mineralogical characterizations from high spectral resolution satellite observations.

The next step is to extend the retrieval over land, which requires consideration of the still poorly known infrared surface emissivities at high resolution. This will provide a unique global monitoring of dust sources over desert.

Acknowledgements. We are grateful to P. Dubuisson for his help in coupling 4A and DISORT, and to C. Crevoisier for his help in using AIRS data. Thanks are due to D. Tanré, P. Chazette and C. Stubenrauch for their helpful comments, and to Y. Balkanski and N. Scott for reading an earlier version of the manuscript. We thank D. Tanré and his staff for establishing and maintaining the AERONET site at Capo Verde. We would like to acknowledge M.

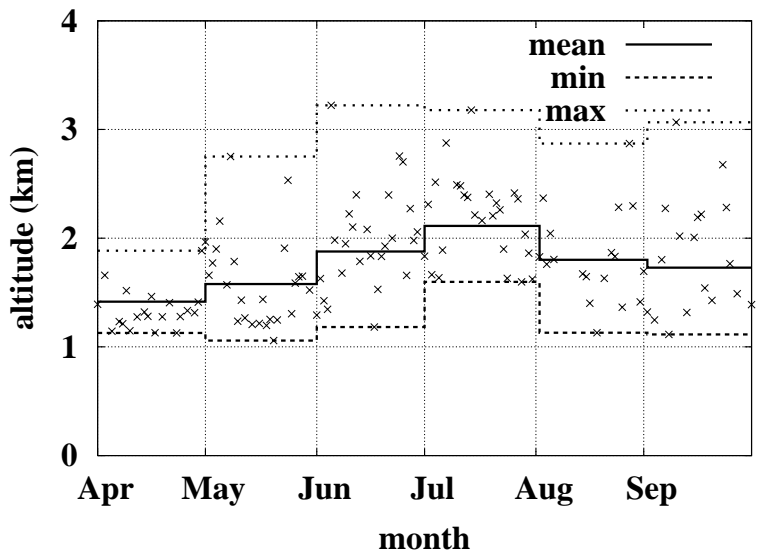

Fig. 6. Evolution of the dust layer altitude in time for the zone 10$20^{\circ} \mathrm{N}, 20-30^{\circ} \mathrm{W}$ (over Capo-Verde), for April to September 2003. Each point represents the average altitude for this zone for one day.

Mishchenko and B. Cairns for their help in studying the impact of the aerosol microphysical properties on our retrieval.

Edited by: U. Lohmann

\section{References}

Ackerman, S., Huang, H.-L., Antonelli, P., Holz, R., Revercomb, H., Tobin, D., Baggett, K., and Davies, J. E.: Detection of clouds and aerosols using infrared hyperspectral observations, 20th International Conference on Interactive Information and Processing Systems for Meteorology, Oceanography, and Hydrology, American Meteorological Society, Seattle, WA, 10-15 January, 2004.

Chédin, A., Scott, N., Wahiche, C., and Moulinier, P.: The improved initialization inversion method - a high-resolution physical method for temperature retrievals from satellites of the TIROS-N series, J. Clim. Appl. Meteorol., 24, 128-143, 1985.

Chevallier, F., Cheruy, F., Scott, N., and Chédin, A.: A neural network approach for a fast and accurate computation of a longwave radiative budget, J. Appl. Meteorol., 37, 1385-1397, 1998.

Chiapello, I., Bergametti, G., Gomes, L., Chatenet, B., Dulac, F., Pimenta, J., and Soares, E. S.: An additional low layer transport of Sahelian and Saharan dust over the North-Eastern Tropical Atlantic, Geophys. Res. Lett., 22, 3191-3194, 1995.

Chomette, O., Legrand, M., and Marticorena, B.: Determination of the wind speed threshold for the emission of desert dust using satellite remote sensing in the thermal infrared, J. Geophys. Res., 104, 31 207-31 215, 1999.

Colarco, P., Toon, O., Redi, J., Livingston, J., Russell, P., Redemann, J., Schmid, B., Maring, H., Savoie, D., Welton, E., Campbell, J., Holben, B., and Levy, R.: Saharan dust transport to the Caribbean during PRIDE: 2 . Transport, vertical profiles, and deposition in simulations of in-situ and remote sensing observations., J. Geophys. Res., 108, 8590, doi:10.1029/2002JD002 659, 2003.

d'Almeida, G. A., Koepke, P., and Shettle, E. P.: Atmospheric aerosols: global climatology and radiative characteristics., A. 
Deepak Publishing, Hampton, Virginia 23666-1340, USA, 1991

Dubovik, O., and King, M.D.: A flexible inversion algorithm for retrieval of aerosol optical properties from sun and sky radiance measurements., J. Geophys. Res.., 105, 20 673-20 696, 2000

Dufresne, J.-L., Gautier, C., Ricchiazzi, P., and Fouquart, Y.: Longwave scattering effects of mineral aerosols., J. Atmo. Sci., 59, 1959-1966, 2002.

Fouquart, Y., Bonnel, B., Brogniez, G., Buriez, J. C., Smith, L., Morcrette, J. J., and Cerf, A.: Observations of Saharan aerosols: results of ECLATS field experiment. Part II: broadband radiative characteristics of the aerosols and vertical radiative flux divergence., J. Clim. Appl. Meteor., 26, 38-52, 1987.

Goldberg, M., Qu, Y., McMillin, L., Wolf, W., Zhou, L., and Divakarla, M.: AIRS near-real-time products and algorithms in support of operational numerical weather prediction, IEEE Trans. Geosci. Remote Sens., 41, 379-389, 2003.

Hess, M., Koepke, P., and Schult, I.: Optical Properties of Aerosols and Clouds: The software package OPAC, Bull. Am. Met. Soc., 79, 831-844, 1998.

Highwood, E., Haywood, J. M., Silverstone, M. D., Newman, S. M., and Taylor, J. P.: Radiative properties and direct effect of saharan dust measured by the C-130 aircraft during Saharan Dust Experiment (SHADE), 2. Terrestrial spectrum, J. Geophys. Res., 108, 8578, doi:10.1029/2002JD002 552, 2003.

Immler, F. and Schrems, O.: Vertical profiles, optical and microphysical properties of Saharan dust layers determined by a shipborne lidar, Atmos. Chem. Phys., 3, 2707-2737, 2003.

IPPC, Working Group I to the Third Assessment Report of the Intergovernmental Panel on Climate Change: Climate change 2001: the scientific basis, Cambridge University Press, Cambridge CB2 2RU, United Kingdom, 2001.

Jacquinet-Husson, N., Arie, E., Scott, N.-A., et al.: The 1997 spectroscopic Geisa databank, J. Quant. Spectrosc. Radiat. Transfer, 62, 205-254, 1999.

Jonquieres, I., Marenco, A., Maalej, A., and Rohrer, F.: Study of ozone formation and transatlantic transport from biomass burning emissions over West Africa during the ariborne Tropospheric Ozone Campaigns TROPOZ I and TROPOZ II., J. Geophys. Res., 103, 19 059-19073, 1998.

King, M., Tsay, S.-C., Ackerman, S., and Larsen, N.: Discriminating heavy aerosol, clouds, and fires during SCAR-B: Application of airborne multispectral data, J. Geophys. Res., 103, 31989 31 999, 1998.

Kinne, S., Lohmann, U., Feichter, J., et al.: Monthly averages of aerosol properties: A global comparison among models, satellite data, and AERONET ground data, J. Geophys. Res., 108, 4634, doi:10.1029/2001JD001 253, 2003.

Lacis, A. and Oinas, V.: A description of the correlated k distribution method for modelling nongray gaseous absorption, thermal emission, and multiple scattering in vertical inhomogeneous atmospheres, J. Geophys. Res., 96, 9027-9063, 1991.

Mahesh, A., Gray, M., Palm, S., Hart, W., and Spinhirne, J.: Passive and active detection of clouds: Comparison between MODIS and GLAS observations, Geophys. Res. Lett., 31, L04 108, doi:10.1029/2003GL018 859, 2004.

Maring, H., Savoie, D., Izaguirre, M., and Custals, L.: Vertical distributions of dust and sea-salt aerosols over Puerto Rico during PRIDE measured from a light aircraft, J. Geophys. Res., 108, 8587, doi:10.1029/2002JD002 544, 2003a.
Maring, H., Savoie, D., Izaguirre, M., Custals, L., and Reid, J. S.: Mineral dust aerosol size distribution change during atmospheric transport, J. Geophys. Res., 108, 8592, doi:10.1029/2002JD002 536, 2003 b.

Mishchenko, M., Travis, L. D., and Lacis, A. A.: Scattering, absorption and emission of light by small particles, Cambridge University Press, Cambridge CB2 2RU, England, 2002.

Prospero, J. and Carlson, T.: Vertical and areal distribution of saharan dust over the western equatorial north Atlantic ocean, J. Geophys. Res., 77, 5255-5265, 1972.

Reid, J., Westphal, D., Livingston, J. M., Savoie, D. L., Maring, H. B., Jonsson, H. H., Eleuterio, D. P., Kinney, J. E., and Reid, E. A.: Dust vertical distribution in the Caribbean during the Puerto Rico Dust Experiment, Geophys. Res. Lett., 29, doi:10.1029/2001GL014 092., 2002.

Remer, L., Tanré, D., Kaufman, Y., Ichoku, C., Mattoo, S., Levy, R., Chu, D., Holben, B., Dubovik, O., Smirnov, A., Martins, J., Li, R., and Ahmad, Z.: Validation of MODIS aerosol retrieval over ocean, Geophys. Res. Lett., 29, doi:10.1029/2001GL013 204, 2002.

Scott, N. and Chédin, A.: A fast line-by-line method for atmospheric absorption computations: the automatized atmospheric absorption atlas, J. Appl. Met., 20, 802-812, 1981.

Scott, N., Chédin, A., Armante, R., Francis, J., Stubenrauch, C., Chaboureau, J.-P., Chevallier, F., Claud, C., and Cheruy, F.: Characteristics of the TOVS Pathfinder Path-B Dataset, Bull. Am. Met. Soc., 80, 2679-2701, 1999.

Sokolik, I.: The spectral radiative signature of wind-blown mineral dust: Implications for remote sensing in the thermal IR region, Geophys. Res. Lett., 29, 2154, doi:10.1029/2002GL015910, 2002.

Sokolik, I., Toon, O., and Bergstrom, R.: Modeling the radiative characteristics of airborne mineral aerosols at infrared wavelengths, J. Geophys. Res., 103, 8813-8826, 1998.

Stamnes, K., Tsay, S.-C., Wiscombe, W., and Jayaweera, K.: Numerically stable algorithm for discrete ordinate-method radiative transfer in multiple scattering and emitting layered media, Appl. Optics, 27, 2502-2509, 1988.

Tanré, D., Kaufman, Y. J., Herman, M., and Mattoo, S.: Remote sensing of aerosol properties over oceans using the MODIS/EOS spectral radiances, J. Geophys. Res., 102, 16971-16 988, 1997.

Vogelmann, A., Flatau, P., Szczodrak, M., Markowicz, K., and Minnett, P.: Observations of large aerosol infrared forcing at the surface, Geophys. Res. Lett., 30, 1655, doi:10.1029/2002GL016 829, 2003.

Volz, F.E.: Infrared optical constants of ammonium sulfate, sahara dust, volcanic pumice, and flyash, Appl. Opt., 12, 564-568, 1973.

Weaver, C., Joiner, J., and Ginoux, P.: Mineral aerosol contamination of TIROS Operational Vertical Sounder (TOVS) temperature and moisture retrievals, J. Geophys. Res., 108, 4246, doi:10.1029/2002JD002 571, 2003.

Yang, S., Ricchiazzi, P., and Gautier, C.: Modified correlated kdistribution methods for remote sensing applications, J. Quant. Spectro. Radiat. Trans., 64, 585-608, 2000. 